\title{
To be or not to be a fan... that's the question
}

\author{
Gilda, no me arrepiento de este amor | Lorena Muños | 2016
}

\author{
Bárbara Navarro*
}

Escuela de Orientación Lacaniana

Recibido 2 de septiembre de 2018; aceptado 19 de octubre 2018

\section{Resumen}

El presente trabajo busca pensar la función que desempeña el fanatismo particularmente en el terreno musical, a la luz de los aportes del Psicoanálisis de orientación lacaniana. A partir de las reflexiones que suscitaron la película "Gilda. No me arrepiento de éste amor", se intenta arribar a algunos argumentos que permitan dar cuenta de las devociones que en el torno de ésta figura musical se realizan. La indagación sobre el origen del fanatismo, su etimología y significado y la función que cumple en la adolescencia, hasta poder pensar su empleo en casos extremos como en la erotomanía. Los conceptos de identificación e identidad serán en el texto los nudos conceptuales desde donde indagar el tema. Por otro lado, el parentesco que siempre ligó al fanatismo con las ideas religiosas y en la actualidad con el discurso capitalista, el mercado y el consumo. Se pretende así abrir la temática introduciendo alguno de sus efectos posibles, como el de la segregación: el fanatismo no admite la diferencia aunque la exalte, de tal manera constituye un modo de rechazo de las diferencias y un intento de borramiento de las singularidades. El trabajo no pretende patologizar a las prácticas de "fans", sino abrir el amplio abanico del que está compuesto, como modo de pensar la función singular que cumple en cada sujeto, ligado a su goce y a su síntoma, destacándolos también como las claves de aquello que se hace refractario en las identificaciones.

Palabras clave: fanatismos | identificaciones | identidad | erotomanía |segregación

To be or not to be a fan... that's the question

\begin{abstract}
The present work seeks to think about the role played by fanaticism particularly in the musical field, in light of the contributions of Psychoanalysis of Lacanian orientation. From the reflections that the film "Gilda. I do not regret this love ", we try to arrive at some arguments that allow to give an account of the devotions that take place in this musical figure. The investigation about the origin of fanaticism, its etymology and meaning and the role it fulfills in adolescence, to be able to think about its use in extreme cases such as erotomania. The concepts of identification and identity will be in the text the conceptual knots from which to investigate the subject. On the other hand, the kinship that always linked fanaticism with religious ideas and currently with capitalist discourse, the market and consumption. It is intended to open the subject by introducing some of its possible effects, such as segregation: fanaticism does not admit the difference, although it exalts it, in such a way it constitutes a way of rejecting differences and an attempt to erase singularities. The work does not pretend to pathologize the practices of "fans", but to open the wide range of which it is composed, as a way of thinking about the singular function that it fulfills in each subject, linked to its enjoyment and its symptom, highlighting them also as the keys of what is made refractory in the identifications.
\end{abstract}

Key words: fanaticisms | identifications | identity | erotomania | segregation

En este breve ensayo no pretendo hacer una interpretación de la película "Gilda". Como decía Freud, el arte no se interpreta desde el Psicoanálisis, sino más bien, nos lleva la delantera, nos enseña.

En tal caso, voy a tratar de transmitir las reflexiones, las preguntas que me ha suscitado. No voy a interpretar tampoco a Gilda, como protagonista y dueña de esa historia. Ninguna tentativa de psicoanálisis silvestre creo ayudaría. No podemos tomar a Gilda como un caso clínico.

Tampoco voy a hablar de cine, ya que no poseo los elementos conceptuales para aventurarme o arriesgarme a hablar del séptimo arte, que miro, admiro, pero desconozco en sus bases.

Voy a hablar de psicoanálisis y del tema de éste ciclo: Fanatismos. Y del subtítulo: ¿De qué lado estás? 
Y particularmente, distorsionando un poco a Hamlet, planteo: "To be or not to be a fan...that's the question"

Recuerdo en mi adolescencia deseaba ser fanática de alguien. Veía con cierta envidia a las chicas que usaban vinchas de Luis Miguel u otros. No envidiaba su gusto por tal cantante, me gustaban muchos, aunque no ese. Lo que deseaba era ser fanática. No me salía, no podía, aunque reconozco haberlo intentado y deseado.

¿Por qué anhelar ser un fanático? Quizás advertía a esa cualidad como protección o refugio de algo. Quizás refugio de la desorientación de una identidad cristalizándose aún en proceso, proceso no sin el adolescimiento propio de esa época de la vida.

Efectivamente ser fanática otorgaba cierta identidad, "fans de los The Cure", o "fans de Menudo", brindaban por lo menos una brújula sobre la imagen que uno debía portar, sobre el modo de comportarse, y ciertas prácticas y usos. Una armadura identificatoria.

No se trataba de la identidad en singular, pero algo es algo... Un buen recurso para ser usado.

De este modo, me permito ingresar al tema del fanatismo como refugio de la identidad. Según Lacan (1967) "las identificaciones son lo que cristalizan en una identidad" (s/p). Este tipo de identificación, de los fans, es del orden de la imagen, y no es probablemente lo más cristalizable en el sentido de diferenciar, de situar lo singular, de apuntar a lo que identifica a cada ser.

Pero si genera otra identidad, una identidad grupal o colectiva. El término identidad en una de sus acepciones significa "igualdad que se verifica siempre, cualquiera sea el valor de las variables que contiene" (Moliner M, 2007, p. 1594). No era difícil advertir en los grupos de fans esa condición de cierta igualdad, al menos desde la imagen.

Ahora bien, podemos pensar que no es lo mismo ser un fans a esa edad de la vida, que en la adultez u otras... Pero me atrevo a decir que sí, que se trata de lo mismo.

¿Qué es ser fanático? Significa, según Moliner M (2007), "ser partidario exaltado e intolerante de una creencia" (p.84). Sitúo que la dificultad para convertirme en fan no era la exaltación, esta podía sobrevenir por otras cuestiones, mucho menos la intolerancia, eso había de sobra. La dificultad era ser partidario exclusivo a algo. Si a uno le gustaba "The Cure", "The Police", "Pink Floyd", "Sumo", "Borges" o "Heidi" es difícil construir una imagen con ese conjunto heterogéneo. Resultado del intento: un pachtworkabsolutamente singular, disperso que no genera per se una pertenencia a ningún grupo social.

Desde allí podemos inferir que ser fans genera una posibilidad de lazo social, una pertenencia a determina- da comunidad autopropuesta, elegida. Ser fanático no es una obligación, o por lo menos no un mandato directo. Indirecto sí, ya veremos más adelante de qué modo.

¿Los fanatismos son nuevos? Desde ya podemos decir que no. Siempre existieron. La palabra "fanatismo" proviene del latin "fanitiche", según la obra de Bautista, era un sujeto que pertenecía a una entidad pública o privada extremadamente estricta y se lo llamaba para realizar acciones en las que debia estar a plena disposición. Asimismo, la palabra "fanático" proviene del sustantivo "fanum" que significa templo, por lo tanto, fanático era toda persona que pertenecía al templo (Javaloy F, 1984, p. 84). Vale la pena recordar al fanatismo religioso. Este se dice que comienza con la aparición de las religiones monoteístas. Sus adeptos sostenían la creencia de ser los poseedores de una única "fe verdadera". Principio que justificó guerras de religión.

Vemos entonces que el fanatismo no acepta la dispersión, ni la diferencia. No solidariza con el pachtwork singular y como tal actúa como argumento de segregación.

No podemos decir que esto es absolutamente aplicable a los fanatismos musicales u otros que comparados con los religiosos son de liviana índole, aunque nos consta que más de una vez produjo muertes.

En el ámbito musical el fanatismo se introdujo en nuestro país con la ópera, entre fines del siglo XIX y principios del XX. En ese período los intérpretes nacionales escaseaban y el público argentino era entretenido en los escenarios de los teatros por artistas traídos desde Europa, quienes eran recibidos con distinción y honor.

Pero es en la década del 60, a partir de la banda inglesa, de Liverpool, donde el fenómeno de la beatlemanía impulsó un contagio masivo y mundial. El fanatismo llevado a su extremo, es lo que derivó en la muerte de su líder y cantante John Lennon, llevada adelante por el fan Mark David Chapman, quien confesara tiempo después, su ferviente pasión de convertirse en alguien tan famoso, igual que aquél a quien asesinó. ${ }^{1}$

Entramos en el terreno de algo que pareciera amor, pero que más que amor podríamos calificar de pasión extrema: la erotomanía. Sobre ésta condición se hallan referencias tempranas en la obra de Hipócrates, Erisistrato, Plutarco y Galeno. En la literatura psiquiátrica fue mencionado por primera vez en 1623 en el tratado Maladie d'Amour ou Melancolie Erotique, de Jacques Ferrand. Ha sido denominado de diversas formas: "psicosis de la vieja doncella", "paranoia erótica” e "ilusiones eróticas autoreferentes" hasta que se consolidó el uso de los tér- 
minos erotomanía y/o síndrome de Clerambault quien en 1921 publicó un extenso informe acerca del tema en Les Psychoses Passionelles. ${ }^{2}$

Este último fue justamente quien dirigió la tesis sobre la paranoia con la que se doctoró Jacques Lacan. El trabajo ahondó en un caso mediático ya que Aimée (llamada en realidad Margueritte) trató de asesinar a una conocida actriz con la que se sentía identificada y a la que a la vez identificó como su perseguidor. Lacan describió con el caso la paranoia de autopunición, al evidenciar que el delirio terminó con el paso al acto y que Aimée estaba tratando de asesinar en la Sra $\mathrm{Z}$ a ella misma pues $\mathrm{Z}$ representaba lo que ella deseaba, sus aspiraciones secretas. Con estos aportes revolucionó la concepción de la psicogénesis de la paranoia que por aquel entonces se encontraba sepultada en las ideas constitucionales que imperaban en la psiquiatría oficial.

De todos modos, no podemos calificar a todo tipo de fanatismo como patología. Se tratará de medir en todo caso, la tonalidad del mismo. El abanico del fanatismo es de lo más variopinto. Como en la curva de Gauss, también aquí podemos ubicar grados de fanatismo. Pero más allá de eso, de la cantidad, nos interesa verificar qué función cumple en cada oportunidad y para cada sujeto.

Nuestra búsqueda entonces no es sólo quedarnos con el estudio antropológico de los clubs de fans como fenómeno social y colectivo, sino poder ir más allá, y advertir que el conjunto aparentemente homogéneo bajo tal nominación, se nos revela como heterogéneo, diverso y múltiple cuando atendemos a su funcionamiento singular.

Pero volvamos acerca de algo que planteo antes. ¿Es una elección libre el fanatismo? ¿Es un mandato? En los casos de paranoia comentados, no cabe duda que se trata de un mandato que genera una respuesta exacerbada, sin medida alguna. Seguramente en otros no tan extremos, también puede serlo, un mandato superyoico: de "deber aspirar a ser como..."," tener que ir al recital”, etc. Al ser mandato, el goce es padecimiento, ya que no es algo que se elija, sino que también de otro modo se impone. No es raro observar fanáticos llorando, gritando, realizando renuncias (largas filas para comprar un boleto, sacrificios económicos, y otros) para estar cerca de sus ídolos o deidades musicales. Así algo que se manifiesta en apariencia como satisfactorio implica una renuncia de fondo.

$¿ Y$ el mandato indirecto? Este, si lo podemos calificar como indirecto, ya que tanto no lo es, es el del mercado. ¿Cómo el mercado interviene en esto? Fabricando ídolos, estimulando a los sujetos a la idolatría. ¿Con qué fin? El consumo.
En el terreno de la música, la consolidación de los grupos de fanáticos, fue un efecto de la industria discográfica. Los había antes pero dispersos, no congregados. Esto fue adquiriendo tal relieve que muchos tienen reglas, una razón social, objetivos, y más. De algún modo podemos pensar que el mercado fabrica ídolos susceptibles de generar fanáticos, a fin de contagiar su misión: la venta.

Los fanatismos otorgan aquello que Freud caracterizaba como propio de las religiones, generar un sentimiento oceánico de comunidad. Un refugio a los malestares de la vida real, un tapón al agujero que puede implicar la existencia. Otorgar entonces cierto poder, encontrar en el ídolo dones que permitan identificarlo como dios o como santo, tiene una eficacia mucho mayor que es la que otorga la religión.

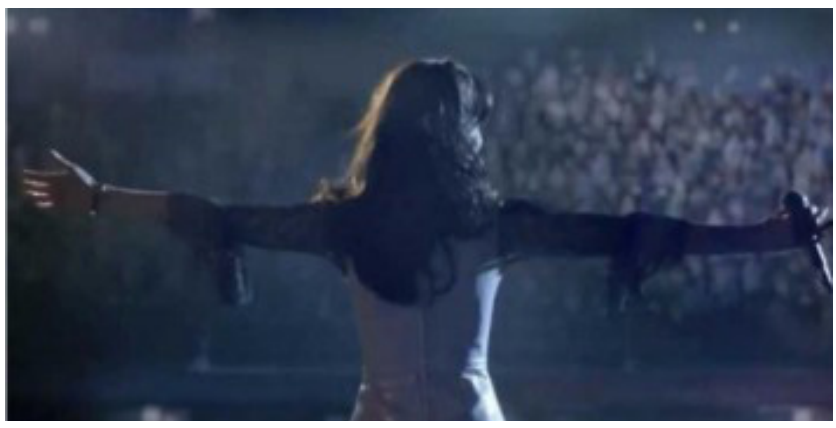

Respecto a Gilda, sus seguidores no la consideran "diosa", sino "santa". Su versión es entonces humanizada. En hebreo el término "santo" significa "apartamiento" o "separación". De alguna manera se trataría de una persona común que pudo ser apartada, separada y reconocida de manera especial. El santo es alguien que pudo ser elegido por Dios, distinguido por su particular elevación ética, por virtudes especiales en las que se destaca sobre todo el amor. La santidad adquiere particular reconocimiento luego de la muerte. Si bien alguien puede ser objeto de culto, estando vivo, lo es aún más luego de su muerte, por entenderse, por creer que se encuentran más cerca de la divinidad, de la compañía de Dios en ese momento.

Queda mucho por investigar en relación a ésta amplia temática. Pero nos permitimos apuntar a la idea de que más allá de las identificaciones, de la identidad, de la posibilidad de lazo, de pertenencia, el fanatismo no sólo se reduce a eso. No podemos soslayar lo real en esto: la función que el goce desempeña. Al servicio de qué se vuelca el amor-odio para determinado sujeto. Cuál es el sustrato de base de tal ingeniería.

Asistimos a un doble movimiento en la actualidad: creciente homogenización, todos iguales, borramien- 
to de las diferencias sexuales, culturales, producto de la globalización, de masificación a la que apunta el discurso del capitalismo: todos consumidores. Al mismo tiempo, un fuerte empuje a la diferenciación en el exaltamiento de los goces particulares, en una especie de exageración de ciertas singularidades, base de ciertos fundamentalismos que hoy retornan con fuerza.

“¿De qué lado estás?” Es la contracara del igualitarismo capitalista. Introduce una diferencia. Pero al modo de una trampa, de una puerta que se cree que abre a otra cosa, conduce al mismo laberinto, termina ingresando a los sujetos a la segregación.
Para concluir: el fanatismo no admite la diferencia aunque la exalte. Estar de un lado, es rechazar el otro. Es pretender a todos iguales, en un intento de borramiento de las singularidades.

¿Qué aporta el psicoanálisis en relación a ésta temática? Me parece que lo que aporta es la posibilidad de tomar un poco de aire por fuera del tufo del pegoteo masivo. Un despertar de los efectos narcóticos que estas prácticas pueden tener en oportunidades extremas. La política de lo singular que implica el psicoanálisis, hace que siempre en las identificaciones pueda encontrarse un punto refractario, el del propio goce, el del propio síntoma.

\section{Referencias}

Freud, S. (1921 [1976]). Psicología de las masas y análisis del yo. En Obras Completas. Buenos Aires. Editorial Amorrortu.

Freud, S (1930). El malestar en la cultura. En Obras completas. México: Amorrortu.

Javaloy, F (1984). "Introducción al estudio del fanatismo”. Edicions Universitat de Barcelona. Barcelona.

Lacan, J (2003). El Seminario, Libro 8 “La transferencia”. Paidós. Buenos Aires.

Lacan, Jacques, El Seminario, Libro 24, “Lo no sabido que se sabe”. Obra inédita.

Miller, J (2005). El Otro que no existe y sus comités de ética. Paidós. Buenos Aires.

Moliner, María (2007). “Diccionario del uso del español” Editorial Gredos. Madrid.

$1 \quad$ https://es.wikipedia.org/wiki/Mark_David_Chapman

2 https://www.researchgate.net/publication/10854135_Erotomania_A_conceptual_history 